\title{
Effect of Cereal Type on the Performance, Gastrointestinal Tract Development and Intestinal Morphology of the Newly Hatched Broiler Chick
}

\author{
Donald V. Thomas and Velmurugu Ravindran \\ Institute of Food, Nutrition and Human Health, Massey University, Palmerston North, New Zealand
}

\begin{abstract}
The objective of this study was to determine the effect of cereal type on the performance and gastrointestinal responses of broiler chicks. Diets based on wheat, sorghum and maize, and formulated to contain similar levels of major nutrients, were fed to broiler chicks from days 1-14 post hatch. The wheat-based diet also contained a commercial xylanase at $0.075 \%$ level. Birds fed the maize-based diet grew faster $(P<0.05)$ than those fed the sorghum-based diet. Weight gains of birds fed the wheat-based diet did not differ $(P>0.05)$ from those fed either the maize- or sorghum-based diets. Birds fed the maize-based diet had the lowest and those fed the sorghum-based diet had the highest feed per gain, but the differences were not significant $(P>0.05)$. The treatments had no effect $(P>0.05)$ on gastrointestinal tract or intestinal morphometry measurements. Performance differences observed between birds fed maize- and sorghum-based diets were not related to gastrointestinal tract or intestinal morphology.
\end{abstract}

Key words: broiler chick, Cereal type, gastrointestinal tract development, performance

J. Poult. Sci., 45: 46-50, 2008

\section{Introduction}

Composition of pre-starter diet can influence the subsequent growth and development of broiler chickens. Because of their immature digestive system, newly hatched chicks are less efficient in utilising nutrients and it is possible that they may benefit from diets based on easily digested cereals. Cereals are known to contain varying levels of non-starch polysaccharides (NSP) giving rise to differing viscosity levels in both the feeds manufactured from these cereals and in the digesta of chickens fed these feeds. Increased digesta viscosity is known to reduce digestion and absorption of a range of nutrients (Annison, 1993). Wheat-based diets are more viscous than maizebased diets as they contain higher levels of NSP and as a result are less efficiently utilised than maize-based diets by poultry, especially the young chicks. Sorghum, another common cereal, is a good energy source with the apparent metabolisable energy (AME) level greater than wheat (Hughes and Choct, 1999), but may contain significant amount of tannins that have been shown to reduce amino acid digestibility (Ravindran et al., 2005), feed intake, growth and feed efficiency in poultry (Nyachoti et al., 1997).

Received: August 2, 2007, Accepted: October 1, 2007

Correspondence: V. Ravindran, Institute of Food, Nutrition and Human Health, Massey University, Private Bag 11 222, Palmerston North, New Zealand. (E-mail: V.Ravindran@massey.ac.nz)
The gastrointestinal tract is a major consumer of nutrients in animals, with rapid cell turnover utilising significant quantities of both nutrients and energy. An increase in the proportional size of the gastrointestinal tract will therefore increase the nutrient demand by the gut and reduce the feed efficiency of the bird. It has been shown that cereals with high NSP level may increase the size of the gastrointestinal tract. A significant positive correlation between arabinoxylan level in wheats and the relative weights of the duodenum, jejunum and ileum has been reported by Steenfeldt (2001). It is known that diet composition may produce microscopic alterations in the intestinal mucosa (Yamauchi, 2002) and it is possible that dietary NSP levels may also influence the morphology of the gastrointestinal tract. Iji (1999) found that guar gum and xanthin gum significantly increased crypt depth of both the jejunum and ileum, suggesting that NSP may promote gastrointestinal tract cell turnover. Greater crypt depth indicates increased villus cell proliferation, and therefore an increase in nutrients being utilised by the gastrointestinal tract. Thus it is tempting to hypothesize that the differences in performance generally observed between different cereal-based diets (Ao and Choct, 2004) may be related, partly, to differences in relative gastrointestinal tract size and intestinal morphology. However, published data on the effects of manipulation of cereal types on gastrointestinal tract development are limited.

The aim of this research was to examine the performance and gastrointestinal responses of the newly hatched 
broiler chick fed diets based on wheat, sorghum or maize from 1 to 14 days of age.

\section{Materials and Methods}

All experimental procedures were approved by the Massey University Animal Ethics Committee and complied with the Massey University Code of Ethical Conduct for the Use of Live Animals for Teaching and Research. Diets

Three dietary treatments based on wheat, sorghum and maize were used in the trial. The diets were formulated to have similar levels of metabolisable energy, essential amino acids, calcium and available phosphorus. The diets were formulated to meet or exceed the NRC (1994) requirements for all nutrients. The wheat-based diet was supplemented with a commercial xylanase as this is standard commercial practice and necessary if the research results are to have practical relevance. All diets were steam pelleted at $60^{\circ} \mathrm{C}$. The ingredient composition of the diets is shown in Table 1.

\section{General Procedures}

Day-old male broilers (Ross 308) were weighed and allocated to 18 cages of eight chicks each. Each dietary treatment was then assigned to six replicate cages. The chicks were housed in 3-tier electrically heated brooder

Table 1. Composition and calculated analysis (g/100g as fed) of diets based on wheat, sorghum and maize

\begin{tabular}{|c|c|c|c|}
\hline Ingredient & Wheat diet & Sorghum diet & Maize diet \\
\hline Wheat & 65.76 & - & - \\
\hline Sorghum & - & 61.08 & - \\
\hline Maize & - & - & 58.62 \\
\hline Soybean meal & 27.34 & 32.19 & 35.18 \\
\hline Soybean oil & 2.73 & 2.09 & 1.78 \\
\hline Dicalcium phosphate & 2.03 & 1.91 & 2.17 \\
\hline Limestone & 0.34 & 0.94 & 0.78 \\
\hline Salt & 0.14 & 0.16 & 0.23 \\
\hline Lysine. $\mathrm{HCl}$ & 0.34 & 0.29 & 0.18 \\
\hline DL-methionine & 0.24 & 0.33 & 0.25 \\
\hline L-threonine & 0.12 & 0.08 & 0.03 \\
\hline Sodium bicarbonate & 0.36 & 0.33 & 0.18 \\
\hline $\begin{array}{l}\text { Vitamin- trace mineral } \\
\text { premix }^{1}\end{array}$ & 0.30 & 0.30 & 0.30 \\
\hline Xylanase $^{2}$ & + & - & - \\
\hline \multicolumn{4}{|l|}{ Calculated analysis } \\
\hline $\mathrm{AME}, \mathrm{MJ} / \mathrm{kg}$ & 12.5 & 12.5 & 12.5 \\
\hline Crude protein & 22.0 & 22.0 & 22.0 \\
\hline Lysine & 1.35 & 1.35 & 1.35 \\
\hline Methionine + cystine & 0.95 & 0.95 & 0.95 \\
\hline Calcium & 0.95 & 0.95 & 0.95 \\
\hline Available phosphorus & 0.48 & 0.48 & 0.48 \\
\hline
\end{tabular}

${ }^{1}$ Supplied per kilogram of diet: antioxidant, $100 \mathrm{mg}$; biotin, $0.2 \mathrm{mg}$; calcium pantothenate, $12.8 \mathrm{mg}$; cholecalciferol, $60 \mu \mathrm{g}$; cyanocobala$\mathrm{min}, 0.017 \mathrm{mg}$; folic acid, $5.2 \mathrm{mg}$; menadione, $4 \mathrm{mg}$; niacin, $35 \mathrm{mg}$; pyridoxine, $10 \mathrm{mg}$; trans-retinol, $3.33 \mathrm{mg}$; riboflavin, $12 \mathrm{mg}$; thiamine, $3.0 \mathrm{mg}$; dl- $\alpha$-tocopheryl acetate, $60 \mathrm{mg}$; choline chloride, $638 \mathrm{mg}$; Co, $0.3 \mathrm{mg}$; Cu, $3 \mathrm{mg}$; Fe, $25 \mathrm{mg}$; I, $1 \mathrm{mg}$; Mn, $125 \mathrm{mg}$; Mo, $0.5 \mathrm{mg}$; Se, $200 \mu \mathrm{g} ; \mathrm{Zn}, 60 \mathrm{mg}$.

${ }^{2}$ Kemzyme, Kemin Industries, Singapore, added $0.075 \mathrm{~g} / 100 \mathrm{~g}$ diet. pens with $400 \mathrm{~cm}^{2} /$ bird space allocation. Brooding temperature was maintained at $32^{\circ} \mathrm{C}$ on day 1 decreasing to $27^{\circ} \mathrm{C}$ on day 14 . Ventilation was controlled by a central ceiling extraction fan and wall inlet ducts. Feed and water were available at all times. Bodyweight and feed intake were measured at weekly intervals. Moisture loss from the feed was measured over the first seven days and feed intake adjusted. Mortality was recorded on a daily basis. The trial lasted for 14 days.

\section{Collection and Processing of Samples}

On day 14, two birds per replicate pen were weighed and killed by intravenous injection of sodium pentobarbitone and the gastrointestinal tract removed. The lengths of the intestinal segments (duodenum, jejunum, ileum) and caeca were obtained. The weights of the liver and pancreas, and empty weights of proventriculus, gizzard, duodenum, jejunum, ileum and caecum were recorded.

Two more birds per replicate were euthanased and tissue samples were obtained for gut morphological measurements. The gut samples were taken from the following four sites: proximal duodenum (the top of the descending portion of the duodenal loop), duodenal loop (the base of the duodenal loop), distal duodenum/proximal jejunum (at the top of the ascending portion of the duodenal loop) and distal jejunum/proximal ileum (around Meckel's diverticulum). The samples were immediately fixed in Bouin's fluid for a 24 hour period and then stored in a $70 \%$ alcohol solution until further processing.

\section{Morphological Measurement}

Gut samples were fixed in Bouin's solution and then stored in a 70\% alcohol solution before being paraffinembedded. Each fixed sample was then embedded into wax, and sectioned at a thickness of $7 \mu \mathrm{m}$, stained with alcian blue/haematoxylin-eosin and examined by light microscopy. Five intestinal segments were fixed in each slide and the slides were viewed on a Zeiss Axiophot microscope. Visual measurements of villus height, crypt depth and epithelium thickness were made on 10 villi at 100x and 200x magnifications using imaging software (Image Pro Plus, Version 4.1.0.9, Media Cybernetics, Silver Spring, MD).

\section{Data Analysis}

The data were analysed by analysis of variance using the General Linear Model procedure of the SAS ${ }^{\circledR}$ (SAS Institute, 1997) with pen means as the experimental unit for performance data. Morphological measurements were based on individual bird measurements. Differences were considered to be significant at $P<0.05$ and significant differences between means were separated by the Least Significant Difference test.

\section{Results}

\section{Performance data}

The performance data are shown in Table 2. Birds fed the maize-based diet grew faster $(P<0.05)$ than those fed the sorghum-based diet. Growth rate for the wheat- based diet did not differ $(P>0.05)$ from either maize- or sorghum- 
Table 2. Weight gain, feed intake and feed per gain of male broiler chicks fed diets based on wheat, sorghum or maize ${ }^{1}$

\begin{tabular}{cllccc}
\hline \hline \multirow{2}{*}{$1-7$ days } & Wheat & Sorghum & Maize & Pooled SEM \\
& Weight gain, g/bird & $142^{\mathrm{ab}}$ & $131^{\mathrm{b}}$ & $148^{\mathrm{a}}$ & 3.8 \\
& Feed intake, g/bird & 154 & 151 & 160 & 5.1 \\
& Feed per gain g/g & 1.108 & 1.155 & 1.093 & 0.030 \\
1-14 days & Weight gain, g/bird & $438^{\mathrm{ab}}$ & $422^{\mathrm{b}}$ & $463^{\mathrm{a}}$ & 10.8 \\
& Feed intake, g/bird & 568 & 553 & 588 & 13.6 \\
& Feed per gain, g/g & 1.304 & 1.324 & 1.277 & 0.025 \\
\hline
\end{tabular}

${ }^{\mathrm{a}, \mathrm{b}}$ Means in the same row with different superscripts are significantly different $(P<0.05)$.

${ }^{1}$ Mean of six replicates (8 birds/ replicate).

Table 3. Relative weights (g/100 g body weight) and relative length $(\mathrm{cm} / 100 \mathrm{~g}$ body weight) of gastrointestinal tract segments in male broiler chicks fed diets based on wheat, sorghum or maize ${ }^{1,2}$

\begin{tabular}{|c|c|c|c|c|}
\hline & Wheat & Sorghum & Maize & SEM \\
\hline \multicolumn{5}{|l|}{ Relative weight } \\
\hline Liver & 3.39 & 3.25 & 3.23 & 0.14 \\
\hline Pancreas & 0.38 & 0.34 & 0.34 & 0.02 \\
\hline Proventriculus & 0.63 & 0.67 & 0.62 & 0.04 \\
\hline Gizzard $^{3}$ & 1.64 & 1.87 & 1.69 & 0.07 \\
\hline Duodenum & 1.02 & 1.02 & 0.99 & 0.05 \\
\hline Jejunum & 2.06 & 1.94 & 2.09 & 0.07 \\
\hline Ileum $^{4}$ & 1.65 & 1.72 & 1.50 & 0.07 \\
\hline Small intestine ${ }^{5}$ & 4.73 & 4.68 & 4.57 & 0.16 \\
\hline Caeca & 0.38 & 0.42 & 0.37 & 0.02 \\
\hline \multicolumn{5}{|l|}{ Relative length } \\
\hline Duodenum & 4.55 & 4.43 & 4.31 & 0.14 \\
\hline Jejunum & 12.18 & 12.15 & 12.17 & 0.40 \\
\hline Ileum & 11.12 & 11.69 & 11.10 & 0.35 \\
\hline Small intestine $e^{5}$ & 27.85 & 28.27 & 27.58 & 0.79 \\
\hline $\mathrm{Caeca}^{4}$ & 2.20 & 2.25 & 1.95 & 0.08 \\
\hline
\end{tabular}

${ }^{1}$ Differences were not statistically significant $(P>0.05)$.

${ }^{2}$ Mean of 12 observations (six replicates $\times 2$ birds/replicate); determined on day 14 posthatch.

${ }^{3} P=0.09$.

${ }^{4} P=0.07$

${ }^{5}$ Duodenum + jejunum + ileum.

based diets. There was no difference $(P>0.05)$ in feed intake between the three dietary treatments, although there was a numerical trend for feed intake to increase from sorghum to wheat to maize diet, which paralleled weight gain of the birds. There was a numerical improvement in feed per gain from sorghum to wheat to maize, but the differences were not significant $(P>0.05)$. The patterns in performance over the two week trial period were similar to those for the first week.

\section{Gastrointestinal tract measurements}

The effects of cereal type on the relative weights and lengths of gastrointestinal tract segments are shown in Table 3. There were no treatment differences $(P>0.05)$ for any of the parameters, but there was a tendency for birds fed sorghum based diets to have a larger gizzard $(P$ $=0.09)$ and ileum $(P=0.07)$. The lengths of the duodenum, jejunum, ileum and caeca and small intestine showed
Table 4. Intestinal morphological measurements of male broiler chicks fed diets based on wheat, sorghum and maize ${ }^{1,2}$

\begin{tabular}{lrrrc}
\hline \hline & Wheat & Sorghum & Maize & $\begin{array}{c}\text { Pooled } \\
\text { SEM }\end{array}$ \\
\hline Proximal duodenum $(\mu m)$ & & & Fet & \\
Villous tip-crypt base & 1530 & 1478 & 1526 & 225 \\
Villous height & 1303 & 1241 & 1296 & 200 \\
Crypt depth & 211 & 197 & 201 & 53 \\
Epithelial thickness & 41 & 38 & 37 & 7.6 \\
Duodenal loop $(\mu m)$ & & & & \\
Villous tip-crypt base & 1791 & 1793 & 1795 & 262 \\
Villous height & 1562 & 1556 & 1572 & 231 \\
Crypt depth & 215 & 209 & 211 & 50 \\
Epithelial thickness & 44 & 43 & 42 & 8.1 \\
Duodenum/jejunum $(\mu m)$ & & & & \\
Villous tip-crypt base & 1075 & 1069 & 1114 & 175 \\
Villous height & 879 & 876 & 902 & 154 \\
Crypt depth & 189 & 196 & 198 & 42 \\
Epithelial thickness & 38 & 40 & 44 & 9.3 \\
Jenunum/ileum $(\mu m)$ & & & & \\
Villous tip-crypt base & 810 & 723 & 812 & 130 \\
Villous height & 542 & 586 & 660 & 108 \\
Crypt depth & 149 & 138 & 150 & 34 \\
Epithelial thickness & 33 & 31 & 34 & 4.7 \\
\hline
\end{tabular}

${ }^{1}$ Differences were not statistically significant $(P>0.05)$.

${ }^{2}$ Mean of 12 observations (six replicates $\times 2$ birds/replicate); determined on day 14 posthatch.

no treatment differences $(P>0.05)$ although birds fed the maize based diet tended $(P=0.07)$ to have shorter caeca. Morphological measurements

The influence of dietary treatments on the morphological measurements at the four sampling sites is summarised in Table 4. No significant treatment differences $(P>$ 0.05 ) were observed at any of the four sites measured. All morphological measurements showed a high degree of variation, suggesting that a larger sample size would be necessary for any significant differences to be detected. The only significant effect was the effect of sampling sites on villous height $(P<0.01)$. The villous height increased from proximal duodenum to duodenal loop and then decreased to distal duodenum and distal jejunum.

\section{Discussion}

Non-starch polysaccharide levels in wheat are higher 
and more variable than those of maize (Choct, 1997), giving rise to a high variability in chicken performance. This is attributed, in part, to increases in digesta viscosity in wheat based diets which may lower nutrient digestion by impeding the diffusion of digestive enzymes and their substrates and products (Annison, 1993) or through viscosity-microflora interactions (Hubener et al., 2002). Nonstarch polysaccharides have also been shown to increase the size of organs of the gastrointestinal tract (Jorgensen et al., 1996) and to affect intestinal morphology (Iji, 1999), both of which may reduce the efficiency of feed utilisation.

Results from the current trial showed the chicks fed the maize-based diet grew faster and had a numerically lower feed per gain than those fed the sorghum-based diet. The performance of birds fed the wheat-based diet, however, was not significantly different from either the maize- or sorghum-based diets. Based on these reported differences in NSP levels in the three cereals (Choct, 1997), it was anticipated that chicks fed the maize- and sorghum-based diets would grow faster and more efficiently than those fed the wheat based diet. Thus the present findings were unexpected, but may be explained by the fact that the addition of a commercial xylanase in the present study which may have which may have ameliorated the digesta viscosity of this diet and reduced the anti-nutritive effect of wheat non-starch polysaccharides on bird performance (Annison and Choct, 1991; Bedford and Schulze, 1998). The wheat-based diet was supplemented with xylanase because this is standard commercial practice and it was decided to be necessary if the research results are to have practical relevance. Comparing bird performance of birds fed wheat, sorghum and maize based diets, Ao and Choct (2004) found that birds fed diets based on sorghum and maize grew faster and had better feed efficiency than those fed a wheat-based diet and that maize fed chickens grew more efficiently than those fed the sorghum diet. However, in their study, exogenous xylanase was not added to the wheat-based diet.

Published data comparing the feeding value of sorghum with other common cereals are equivocal. Tulasi et al. (2004) found that substituting sorghum for maize gave a similar growth rate, but a higher feed per gain in the chicks fed the sorghum based diets. However, Connor et al. (1976) compared the AME of sorghum and maize hybrids and found significant hybrid differences for sorghum. Black et al. (2005) reported that available energy is utilised less efficiently in sorghum than in wheat possibly because sorghum protein has a lower digestibility than wheat protein. Another possible reason for the lower performance of the sorghum diet may be the presence of tannins, which have anti-nutritional effects including reduced protein digestibility and poor feed efficiency (Nyachoti et al., 1997; Ravindran et al., 2005).

Dietary levels of NSP have been shown to influence the size of the gastrointestinal tract with a higher NSP level increasing both the length of the tract, and the relative weights of the duodenum, jejunum, ileum and caeca (Jor- gensen et al., 1996; Steenfeldt, 2001). In the present study, cereal type had no effects on the relative weights or lengths of the gastrointestinal tract. As noted earlier, the addition of xylanase may explain the lack of effects in birds fed the wheat-based diet.

Non-starch polysaccharides have also been observed to affect gut morphology (Iji, 1999). In the present study, wide variability in intestinal morphology measurements was observed between individual birds and this variability was responsible largely for the lack of significant differences between cereal types. Although not an intended aim of the study, comparison of data along the intestine shows interesting patterns. The villous height was highest and the crypt depth was lowest at the duodenal loop than those at the duodenal/jejunal and jejunal/ileal junctions. These findings appear to be related to intestinal function, as duodenum is the vigorous absorptive segment in avian intestine (Yamauchi, 2002). Our data are also in agreement with those of Yamauchi et al. (1995) who reported that White Leghorn starter chicks had the highest villi in the duodenum followed by lower in jejunum and the lowest in ileum.

The present results suggest that the performance differences observed between birds fed diets based on wheat, sorghum and maize were not related to differences in gastrointestinal tract weights or intestinal morphology, as these parameters were unaffected by dietary cereal type. It would appear that other factors are responsible for observed differences in growth. Probable factors include better nutrient digestion of maize (Ravindran et al., 2005) and the possible presence of tannins in sorghum, which may affect feed intake and digestive efficiency (Nyachoti et al., 1997).

\section{References}

Annison G. The role of wheat non-starch polysaccharides in broiler nutrition. Australian Journal of Agricultural Research, 44: 405-422. 1993.

Annison $\mathrm{G}$ and Choct M. Anti-nutritive activities of cereal nonstarch polysaccharides in broiler diets and strategies minimizing their effects. World's Poultry Science Journal, 47: 232-242. 1991.

Ao $\mathrm{Z}$ and Choct M. Effect of early feeding and grain type on growth and performance of broilers. Proceedings of the Australian Poultry Science Symposium, 16: 116-119. 2004.

Bedford MR and Schulze H. Exogenous enzymes in pigs and poultry. Nutrition Research Reviews, 11: 91-114. 1998.

Black JL, Hughes RJ, Nielson SJ, Tredrea AM, MacAlpine R and van Barneveld RJ. The energy value of cereal grains, particularly wheat and sorghum for poultry. Proceedings of the Australian Poultry Science Symposium, 17: 21-29. 2005.

Choct M. Feed Non-starch Polysaccharides: Chemical Structures and Nutritional Significance, American Soybean Association, Singapore. pp. 12. 1997.

Connor JK, Neill AR and Barram KM. The metabolizable energy content for the chicken of maize and sorghum grain hybrids grown at several geographical regions. Australian Journal of Experimental Agriculture and Animal Husbandry, 16: 699-703. 1976. 
Hubener K, Vahjen W and Simon O. Bacterial responses to different dietary cereal types and xylanase supplementation in the intestine of broiler chicken. Archives of Animal Nutrition, 56: 167-187. 2002.

Hughes RJ and Choct M. Chemical and physical characteristics of grains related to variability in energy and amino acid availability in poultry. Australian Journal of Agricultural Research, 50: 689-702. 1999.

Iji PA. The impact of cereal non-starch polysaccharides on intestinal development and function in broiler chickens. World's Poultry Science Journal, 55: 375-387. 1999.

Jorgensen H, Zhao X, Knudsen KEB and Eggum BO. The influence of dietary fibre source and level on the development of gastrointestinal tract, digestibility and energy metabolism in broiler chickens. British Journal of Nutrition, 75: 379395. 1996.

NRC. National Research Council. The Nutrient Requirements of Poultry. 9th Revised Edition. National Academy Press, Washington DC. 1994.

Nyachoti CM, Atkinson JL and Leeson S. Sorghum tannins: A review. World's Poultry Science Journal, 53: 5-21. 1997.

Ravindran V, Hew LI, Ravindran G and Bryden WL. Apparent ileal digestibility of amino acids in feed ingredients for broiler chickens. Animal Science, 81: 85-97. 2005.

SAS Institute. SAS/STAT ${ }^{\circledR}$ User's Guide: Statistics. Version 6.12. SAS Institute Inc., Cary, NC. 1997

Steenfeldt S. The dietary effect of different wheat cultivars for broiler chickens. British Poultry Science, 42: 595-609. 2001.

Tulasi SL, Reddy AR, Reddy GR, Prasad VLK, Raju MVLN, Rao CLN, Reddy BVS, Rao PP and Ramachandraiah D. 2004. Performance of broilers on sorghum-based diets. International Sorghum and Millets Newsletter, 45: 37-40.

Yamauchi K. Review of chicken intestinal villus histological alterations related with intestinal function. Journal of Poultry Science, 39: 229-242. 2002.

Yamauchi K, Yamamoto K and Isshiki Y. Morphological alterations of the intestinal villi and absorptive epithelial cells in each intestinal part in fasted chickens. Japanese Poultry Science, 32: 241-251. 1995. 